\title{
The Problems of Access: A Crip Rejoinder via the Phenomenology of Spatial Belonging
}

\begin{abstract}
This essay denaturalizes the taken-for-granted meaning of 'access' and interrogates its role and lived meaning in ableist social worlds, with a focus on spaces of higher education. I suggest that legalistic approaches to access need 'cripping' by a disability framework. Currently, these approaches (I) miss the intersubjective sociality of being-in-the-world; (2) they prioritize a narrow conception of access focused on 'physical' access and 'physical' space (a typology I contest); (3) they approach access as frozen in time, rather than as a relational and temporally dynamic process (4); and, finally, they contribute to bureaucratizing and privatizing disability knowledge. I examine 'access' through the lens of belonging by asking how we orient ourselves in spaces shaped by oppressive social norms. I argue that ableist lifeworlds generate serious disorientations for disabled people that are lasting, structurally enforced, and harmful or debilitating.
\end{abstract}

KEYWORDS: access, space, belonging, disability, embodiment

What might it mean for the crips and the misfits to belong in a world that devalues disabled bodyminds? ${ }^{\mathrm{I}}$ To answer this question, I draw on the phenomenology of spatial belonging from a disability studies perspective and investigate the relationship between access, space, and belonging. While discussions of access have taken a variety of scholarly fields and public debates by storm, the notion of access-at least in its common acceptance as a proxy for inclusivity-remains conspicuously absent from the phenomenological literature (Valentine [2020] is a welcome exception). And yet, phenomenology's long-standing interest in space as it is lived and in the embodied ways in which we encounter shared worlds offers a unique vantage point into these questions. After all, strictly speaking, there would be no 'spaces' for us to 'access' and in which to feel as if we 'belonged' (or not) if we did not have a body already involved in the world.

The common-sense approach to access in institutional practice and policy, however, does little to reflect this originary entwinement between body and world. Instead, in the current post-Americans with Disabilities Act (ADA) era in the

I thank Mercer Gary, Emily R. Douglas, Liana Glew, Sarah Clark Miller, and Ted Toadvine for their indispensable comments on earlier versions of this essay. I also thank Marisa Signorini and Matthew Hart for their attentive readings and rereadings. Finally, I thank the reviewer for such a generous reading of my work.

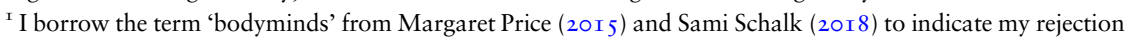
of the metaphysical separation of 'body' and 'mind'. 
United States, access is most often collapsed with the minimal provision of mandated accommodations. In this process, access becomes a matter of legal compliance. When taken in the most general sense, the provision of legal accommodations is popularly imagined as incommensurate with exclusion. New ramps are hurriedly affixed to the main entrance of a centennial building, course syllabi include a mandatory section on disability service offerings, and an official document's technical jargon is synthesized in a reader-friendly list. The building, the course, and the document are 'inclusive' because they are 'accessible', and they are 'accessible' because they check all the required boxes.

The fluency with which we speak about these notions, however, should give us pause. In The Question of Access: Disability, Space, Meaning, disability scholar Tanya Titchkosky warns of the perils of embracing access and inclusion as 'unquestioned values' (Titchkosky 20II: ix). We should instead ask ourselves what effects access has, how and when it materializes (or fails to materialize), who is already included by default, and why some people experience the world as inaccessible in the first place. Exploring the meaning of access fundamentally involves 'the exploration of the meaning of our lives together-who is together with whom, how, where, when, and why?' (Titchkosky 20II: 6). Phenomenologically, then, access lies at the intersection of bodies, worlds, and the everyday practices and norms that determine the intersubjective shape of belonging. Throughout this essay, I adopt this phenomenological framing of access. I take seriously Titchkosky's invitation to denaturalize the taken-for-granted meaning of access and to interrogate its role and lived meaning in ableist social worlds, with a focus on spaces of higher education. Put another way, I wish to transform access into a problem again.

What I call the problems of access includes the legalistic approaches to access in US higher education contexts. Compliance-based, highly bureaucratized approaches to disability inclusion conflate access with the minimal provision of individual accommodations. This strategy falls short phenomenologically on at least four counts: (I) it misses the intersubjective sociality of being-(disabled)-in-the-world; (2) it prioritizes a narrow conception of access focused on 'physical' access and 'physical' space (a typology I contest); (3) it approaches access as frozen in time or as a 'one-time fix', rather than as a relational and temporally dynamic process (4); and, finally, it bureaucratizes and privatizes disability knowledge by devaluing disabled people's lived knowledge of their own bodymind.

How, then, do we inhabit spaces shaped by oppressive norms? While some spaces can serve as a ground for meaningful participation and belonging, others can alienate our presence and make us feel constantly out of place. My disoriented approach to spatial belonging investigates how the ableist, racist, classist, and heterosexist configuration of our shared social worlds harms or forecloses the possibility of belonging for some bodyminds. In particular, I argue that ableist lifeworlds generate serious disorientations for disabled people that are lasting, structurally enforced, and harmful or debilitating. Thinking about access through this broader conceptual lens requires that we reject a narrow, legalistic approach 
to access. Instead, I view access as a tool that is central to the task of transforming oppressive lifeworlds.

\section{The Problems of Access in Higher Education}

The familiarity of institutional language conceals ideals, values, and commitments that recede from view by becoming the unquestioned background of our experience, or simply the way things are. For example, in her study of institutional life, Sara Ahmed examines how the recent buzz around 'diversity' in higher education serves to cancel out the (white) noise of institutional racism. As she explains it, when notions circulate without resistance and do not come up against institutional walls, we should be wary of the work they are doing. When notions are 'detached from histories of struggle over inequality' (Ahmed 20I2: 80), they might circulate better by virtue of this detachment, as empty vessels merely reproducing the status quo. To recognize better how institutional language upholds the status quo, we need what Ahmed calls a 'politics of reattachment' (20I 2: 80). Such a politics investigates the meaning and use of certain notions and allows them 'to be shared as a question' (20I2: $8 \mathrm{I}$ ) by being called into question. The phenomenology of institutional language gains a critical edge by asking how institutional power is served by words that have become ordinary.

This critical strategy motivates my foray into the problems of access in higher education. My aim is to reattach 'access' to meanings it may have lost or that have been obscured by its institutional use. Access has become a self-evident, common-sense good on the neoliberal marketplace of higher education. Like the notion of diversity, the notion of access, too, is buzzing in institutional discourse. However, its meaning remains concealed by layers of familiarity. The very ordinariness of 'access' signals the need for a more careful appraisal of this notion than currently exists in most institutional settings. To borrow Ahmed's formulation, the buzz around access might serve to cover up the 'noisy' complaints of those denouncing the inaccessibility of ableist social worlds. In this scenario, access is presented as a solution to the problems caused by those whose bodyminds must be absorbed into the smooth, predictable course of institutional life. I wish to reverse this order of priority altogether. In this essay, I bring up access not as a solution but as a starting point to reflect on how institutional life congeals around words (and bodyminds) that do not pose a problem. By refusing to reproduce (or to get behind) the habits of an institution, we can begin this inquiry.

Upon closer examination, it is often unclear what the language of access serves to name institutionally. In fact, the notion might precisely accrue its positive value (or become what Ahmed calls a 'happy' word) by being spared this line of questioning. It is generally assumed that access is something we should desire; it is, after all, a necessary condition for inclusion. But this general assumption belies deeper problems. At a political level, the voices and priorities of disabled people (especially poor disabled people and disabled people of color) still take a back seat to those of policy makers, administrators, and large institutions in determining what access means and when access needs are met. Conceptually, the conflation of access with the promise of inclusivity raises a host of critical questions, starting 
with: How are access and inclusion experienced? Whose needs are being 'accommodated' by framing access as a matter of legal compliance? Lastly, by whom, for what purpose, and at what cost are disabled people being welcomed into a more 'inclusive' world?

As I stated, access is commonly viewed as a cornerstone of disability inclusion. It is required to promote the inclusion of disabled students, faculty, and staff in every aspect of institutional life. Eventually, the rhetorical contiguity of these notionsoften alongside the notion of diversity-in mission statements, official letters, annual reports, or grant applications, generates a sense of conceptual continuity. To borrow a formulation by Ahmed, 'one word seems to follow, almost automatically, the other' (2019: 50). These words are 'strengthened' by their association and 'the association between them becomes stronger' (Ahmed 2019: 50). Words trail innocuously behind each other. In this process, they acquire a particular shine. Together, they bounce around pleasantly like a familiar jingle that is 'in tune, in time, not abrasive because it is [shiny and happy]' (Ahmed 20I4). When some words sound shiny and happy, other words, like 'sexism', 'racism', or 'ableism' sound angry and noisy. Even more, they appear to 'have lost their utility' (Ahmed 20I4). Symbols, much like words, can also become happy symbols, as K. Fritsch demonstrates in her essay on the International Symbol of Access. By appearing to 'solve' the problem posed by disability, the symbol 'produces happy feelings [that] circulate with ease' (Fritsch 20I3: I35). Happy words and symbols produce effects that transform how disabled people inhabit institutional spaces. Thus, before outlining what I call the problems of access, I need to scratch at the surface of inclusion.

A common view of inclusion in educational contexts frames it as a 'solution' to the 'problem' of exclusion. In institutional settings, metrics of diversity appraise the inclusion of non-normative (or 'diverse') bodies in spaces that they did not previously inhabit because they were excluded from them. Images of closed doors, of glass ceilings, or of institutional walls, as Ahmed frames it, come to mind. Bodies that previously stood on one side of the closed door are newly invited to cross its threshold. Inclusion purports to transform the architecture of higher education, both materially and symbolically. On this view, one is either included in ('inside') or excluded from ('outside') the university. The reality of inclusion, however, is more complex. Tanya Titchkosky and Rod Michalko explain that the inclusion of disabled students, faculty, and staff in universities relies on their positioning as being both insiders and outsiders: disabled people are 'present yet absent or included as an excludable type' (2012: 74). The aim of disability services, for example, is to ensure that those who are already a part of the lifeworld of a university - albeit as a "naturally excludable type' (Titchkosky 2007: I 49) - are fully included in this world. When disabled people do 'show up,' Titchkosky explains, they show up as a problem. Disabled bodyminds become interrogation points, bold, conspicuous punctuation marks on a blank page, stringing together a series of questions: 'What are they doing here anyway?' (Titchkosky 20I2: 78). What do they want? What do we do with them now? As question marks, they become barriers in the course of everyday life, a site of perplexing uncertainty. Meanwhile, the surface inclusion of disabled people 
consistently elides the question of what has made disability exclusion ordinary in the first place.

I am guarded about the rhetoric of inclusion for two reasons. To begin, as currently understood, this rhetoric fails to identify and disrupt underlying oppressive structures. In other words, the inclusion of disabled bodies in able-bodied spaces does not transform the status quo. While the aim of inclusion is to make room for disabled students into 'so-called regular classrooms' (Wilson 20I7), this process does not disrupt widespread assumptions about the neutrality and normality of nondisabled, neurotypical, white, middle-class classrooms. These classrooms and the institutional worlds that they are a part of were never intended for the 'invasive' presence of 'space intruders' (Puwar 2004). Within normate spaces, nonnormative bodies, such as those of gender nonconforming, racialized, fat, poor, or chronically ill people, are regularly made to feel 'out of place' (an idea I explore below). In sum, while inclusivity has become a pillar of modern neoliberal educational systems, the inclusion agenda does not translate into concrete and structural-rather than merely superficial-changes to oppressive environments.

My second worry is that the current deployment of the rhetoric of inclusion has deeply pernicious effects. It is not only the case that the rhetoric of inclusion does not disrupt the status quo: in many cases, it serves to maintain and guard it under the cover of institutional change. This view requires us to recognize that institutions are not merely passive, ossified structures. Earlier, I mentioned the image of a closed door, of a glass ceiling, or of a wall figuring as a roadblock to inclusion. When we try to change the institution, Ahmed tells us, we come up against a brick wall (2OI 2: 26-27). Images of inert roadblocks, in fact, are often employed as symbols of architectural barriers to access (such as staircases, gates, doors, bathroom stalls, sidewalks). The risk, however, is to imagine that institutions are monolithic and inert. They are not. Instead, the closed doors and brick walls that guard the status quo move strategically; they reflexively track the resistant initiatives of bodies within and outside the institution. When one door opens, another door closes. The rhetoric of inclusion can erect new walls that are less visible and falsely motivate the impression of change.

In light of these shortcomings, and in contradistinction with the 'happy' promise of inclusion, my analysis of access asks how our current framing of access reproduces ableist assumptions about who belongs and who does not belong in institutional lifeworlds. In what follows, I argue that legalistic approaches to access undermine the value of disabled existence and reproduce ableist strategies of exclusion. These approaches (I) miss the intersubjective sociality of being(disabled)-in-the-world; (2) they prioritizes a narrow conception of access focused on 'physical' access and 'physical' space (a typology I contest); (3) they approach access as frozen in time or as a 'one-time fix', rather than as a relational and temporally dynamic process (4); finally, they bureaucratize and privatize disability knowledge by devaluing a person's lived knowledge of their own disabled bodymind.

To clarify: By framing access as a problem, I am neither contesting that claims for access are important nor denying that they have helped secure major gains for 
disabled people. In fact, I fully endorse both points. Disabled activism is and has always been central to the survival and resistance of disabled people in ableist social worlds. I do not wish to denounce the ADA-rights model as a legal framework that yields no benefits whatsoever for disabled people. Accommodations can and do have very concrete implications for disabled people in ableist social worlds. My task in this essay, however, is to highlight the concerning limitations of this model and to invite a broader reflection on the lived meaning of access and belonging. I agree with Titchkosky that 'the most ordinary or acceptable ways to speak of access and its improvement may in fact be a major barrier to the improvement of access' (Titchkosky 20I2: xiii). In institutional contexts, 'some bureaucratic mechanisms of inclusion might actually serve to normalize the ongoing exclusion of disabled people' (2012: xi). What I call 'the problems of access' concern the taken-for-granted meaning of access in institutional discourse and policy.

Although bureaucratic frameworks are central to many aspects of life in modern Western societies, some of us might only realize that bureaucracy is central to our lives when a 'problem' occurs. One might need to navigate the bureaucracy (and implicit hierarchy) of a new workplace or apply to receive social benefits for the first time and find herself overwhelmed by structures that do not seem to capture her specific situation or reflect her needs and priorities. Although she is the one that is seeking help with a problem (such as unusual delays in receiving her paycheck; duplicated requests from the same office), she might find herself encountering new problems or becoming a problem for others. This type of situation is familiar for many disabled people. Disabled people are often figured as 'getting in the way' of how things 'normally' work, or as throwing a wrench in the cogs of a well-oiled system. I take issue with the implicit but pervasive assumption that access is required for those who raise a problem and pose a problem for the university.

In the United States, academic institutions are legally compelled by the ADA and Section 504 of the Rehabilitation Act to provide reasonable accommodations to disabled students, faculty, and staff. My account in this essay focuses largely on the experiences of university students. For obvious reasons, disabled students face many barriers that have an impact on their participation in academic settings. Most research on accommodations currently focuses on the experiences of disabled students, not least because they are at the bottom of the academic food chain and typically hold the least power. But students, of course, are not the only disabled participants in academic life. There are disabled professors (tenured and nontenured), lecturers, invited speakers, visiting scholars, administrative assistants, custodians, librarians, building managers, and chancellors. As Titchkosky observes, while universities are mandated to offer resources for disabled students and typically advertise the accessibility of student-oriented events, they are far less likely to expect, anticipate, or even desire disabled faculty (and staff) in the same spaces (2OII: 45).

For students, the process of applying for accommodations varies across institutions of learning. At my institution, the process is roughly the following: first, a student is required to produce medical documentation for her disability. 
She must provide this documentation before meeting with a counselor. Following an intake interview, she must select accommodations from a list of options preestablished by the university (such as assistance with notetaking, flexed attendance policy, extended testing time). If she is approved for these accommodations, she must come to an agreement about their provision with each instructor at the beginning of every semester. In the end, disabled students are expected to 'fall back in line' and recover the anonymity-what GarlandThomson calls 'visual' or 'material' anonymity (20I I: 596)—afforded to 'normal', 'unmarked' students in the classroom.

When I say that disabled people are expected to 'fall back in line', I mean that they are expected to reintegrate the institutional lifeworld that their demands or questions (recall the image of disabled people as question marks) momentarily fissured. For those of us who work or learn within institutions, these places become a part of what phenomenologists call our everyday lifeworld (Lebenswelt). This lifeworld is experienced as a general horizon for our experience; it is the background against which our lives acquire meaning (or sense). Institutional lifeworlds include objects, persons, discourses, documents (such as forms, bills, and letters), technologies, ideals, and values. Importantly, in the usage that I propose, the people that they include are variously positioned relative to power and privilege. From the start, we are located within this web of complex social relations.

My framing of institutional lifeworlds flatly rejects two ontological assumptions about bodily subjectivity. The first is that beings are separate and autonomous, rather than relationally 'implicated in, informed by, [and] intertwined with other subjectivities' (Maclaren 20I4: 56). Relatedly, I reject the assumption that disability is an individual 'problem' singularly located in one's body, rather than an experience of bodily difference that is dialogically experienced within shared material and attitudinal environments. Against a tendency to view bodily subjectivity as separate from the worlds and relationships that we inhabit, I view others as involved from the start in the constitution of our experience. Others contribute to determine 'the possibilities that we find available or not within our situation, and the positions that we feel ourselves legitimately able to assume' (Maclaren 2018: I9). Our relational entanglements with others can take the form of shared attitudes and beliefs, bodily intimacy and interaction, communication, or, at a much larger scale, political decisions, institutional pressures, laws, or architectural design. For example, disability theorists have argued that 'one cannot be disabled alone' (Titchkosky 20II: 5). The intersubjective sociality of being-in-the-world, and thus of being-disabled-in-the-world, cannot be bracketed from our analysis of access as an interpretive site for the study of the relation between bodies and worlds; it must be fully reattached to it. However, legalistic frameworks focused on the provision of mandated accommodations elude this intersubjective dimension altogether by framing disability as an individual problem.

The second element of my critique concerns the implicit conception of space (and of disability) at stake in current bureaucratic approaches to access. Institutional discourses around access are grounded in imagery, both material and rhetorical, that focuses on what we might call physical disabilities and physical barriers. The International Symbol of Access, for example, consists of a blue square overlaid 
with an unmarked white body in a wheelchair. As a metaphor, access calls to mind 'pathways, barriers, and destinations' (Duchan 2006). When physical barriers are removed, pathways are cleared, and destinations can be reached. My claim is not that structures that facilitate access to material spaces (such as passenger loading zones, elevators, tactile signage, wheelchair-accessible bathrooms) are not important; they absolutely are. Disabled people cannot fully participate in the world if they cannot access basic services and institutions. However, a rigid distinction between physical and nonphysical types of barriers may be more restrictive than it is beneficial and informative for the task of critically reevaluating the meaning of access.

First, focus on physical access centers visible physical impairment over other types of disability (including nonvisible chronic illnesses and psychiatric disabilities). Further, the general assumption that 'physical' accommodations are only required by those with physical disabilities is inaccurate at best. On the one hand, those with physical disabilities require more than what is often called 'physical' access (for example, there might be a wheelchair-accessible ramp outside the building of a department or office whose climate is deeply ableist; adaptive technologies remain inaccessible if they require considerable financial sacrifices). On the other hand, disabled people with nonvisible cognitive, psychiatric, sensory, and environmental disabilities might encounter access barriers that are related to material features of their 'physical' environment (for example, a flickering light in the hallway might be distracting for a professor with ADHD; poor insulation and humidity in the university library can trigger brain fog or emotional fatigue). At the level of lived experience, we do not discriminate between physical and nonphysical elements so sharply, because space is not an objective entity laid out in front of and outside us. Rather, at a more originary level, space is a heterogenous, dynamic milieu that is chiasmically intertwined with our felt experience of our own bodies.

The conception of space that I have in mind bears important similarity to Maurice Merleau-Ponty's (2012) notion of lived space. For Merleau-Ponty, embodied existence is spatialized at its core. For this reason, the ways in which we analyze spatiality should not be limited to what we might colloquially call 'physical space'. Rather, our relationship to space is illustrative of the many dimensions of our lives, be they social, cultural, affective, sexual, political, or practical. What we might call spatial-being-in-the-world includes all of the ways in which we orient ourselves within physical and non-physical milieus. What Merleau-Ponty calls 'the oriented world, or oriented space' (2012: 294) is everywhere where our body 'exists toward [its tasks]' (2OI 2: I30) and installs its 'coordinates'. It is the world around us as a meaningful place where our lives unfold.

Margaret Price's (20I I and 20I6) notion of 'kairotic space' similarly considers the social, material, and affective dimensions of our experience of space. However, Price's closer attention to dynamics of power and to the subtle interactions of those sharing a particular space better highlights the temporally durational, relational, and existentially complex nature of access needs. Kairotic spaces, for Price, include a range of formal and informal academic spaces where 'knowledge is produced and power is exchanged' (Price 20II: 2I). They are fluctuating, 
fast-paced settings or environments in which actors are expected to engage in various interpersonal exchanges and adapt to a changing situation. These types of 'kairotic' milieux include more conventional academic spaces like classrooms, but they also include impromptu hallway conversations, week-long conferences, search committees, job postings, calls for papers, virtual meetings, online discussion boards, as well as the private homes, coffee shops, restaurants and other venues where students, faculty, guests, administrators, and others meet informally. Price's notion of kairotic space invites us to consider the 'radical unpredictability and ambient emergence of disability when [people] gather together' (Price 2016: I 58 ). When coupled with a phenomenological perspective, Price's account allows us to think of material and rhetorical spaces of teaching, learning, knowledgeproduction, evaluation, and collegial exchange in higher education as existentially charged social environments where access is continuously negotiated, rather than achieved once and for all.

The dynamism embedded in this view of access is important, because the relationship between bodies and spaces is labile rather than fixed. A central phenomenological feature of human experience is its relative openness with regard to one's social environment, to interpersonal interactions, to one's needs and capacities, and to particular projects and responsibilities. For this reason, too, access needs are not frozen in time. As a living structure, access is not a switch that we turn on and off, or a box that we can check. Rather, as Price writes, 'many barriers-as well as forms of access-arise in context, shifting as the circumstances and bodyminds of/in a space shift' (Price 20I6: I60). For example, one may be provided with printed materials that facilitate her engagement in a departmental meeting; later that evening, however, she may not be able to meet her colleagues for a drink at the local bar because it is crowded, loud, and poorly lit. Alternatively, a student's participation in a classroom discussion might take a turn from the worst when their previously manageable level of anxiety rises unexpectedly in response to a colleague's remark. Disabled students in a classroom might have conflicting needs (for example, the auditory stimming of one student might be distracting for a disabled peer who uses recording software) or experience different barriers in one setting (such as a laboratory) than they would in another (such as a large auditorium). ${ }^{2}$ These examples clearly illustrate that access needs, much like the flow of experience itself, cannot be entirely anticipated. Accommodation services rarely account for the fact that disabled people sharing a space might have competing access needs or that a person herself might have conflicting needs. Instead, it is most often assumed that there will be at most one 'exception' in every classroom, one bodymind departing from the norm, one disabled person whose needs can be neatly compartmentalized. Access is not 'easy': the messiness of access reminds us of the complexity of lives shared with others.

By prioritizing individualized, 'outcome-based' solutions, we are ill equipped to recognize this complexity. A person's access needs, along with the access needs required by others with whom they share institutional lifeworlds, cannot always

\footnotetext{
${ }^{2}$ I am grateful to my colleague Emily R. Douglas for reminding me of the messiness of access.
} 
be harmonized and predicted through recourse to pre-established, hegemonic forms of accommodation. Yet, legalistic approaches often require that individuals identify their access needs independently of the situations that they might eventually find themselves in (for example, by requiring that requests for accommodations be filled out before a semester begins). This approach to access as frozen in time or as a 'one-time fix' rather than as a dialogical and dynamically unfolding process is concerning. Against this view, a commitment to 'access-as-practice' (Price 2016; see also Powell 2007) reminds us that change, vulnerability, and interdependence are central to our nature as bodily beings. Temporally open-ended arrangements that allow for growth, change, and adaptation are required to transform access into a process, and thereby, into an action verb. ${ }^{3}$

I offer a final element of critique. Ironically, a focus on disability as an individual problem nonetheless mandates external verification. Currently, the legal provision of accommodations requires verification of one's disability by a certified medical practitioner. The bureaucratization (and medicalization) of disability accommodations produces bureaucratic forms of life 'enframing' disabled people 'through bureaucratic activity' (Abrams 201 5: I9). Put otherwise, disabled people are cast as 'entrants' in forms-understood here both as questionnaires and as pre-existing structures-that frame disability as an objective category rather than 'as a materially-situated way of being-in-the-world' (Abrams 20I5: I4). In order to access accommodations, one's disability must fit in a pre-determined form. As Joseph Stramondo explains it, this 'enframing' of disability illustrates that bureaucratic approaches to accommodations are 'procedurally reliant on [a] medical model [of disability]' (2015). Yet, the medical model of disability has long been criticized for its harmful construal of disability as a fixed and readily identifiable marker of dysfunction, deviance, and abnormality. By positioning Western biomedical knowledge as the arbiter of truth about disability, 'the requirement of getting a medical evaluation poses a significant barrier to success that is not presented to a non-disabled academic or students' (Stramondo 20I 5 ). In this sense, the medicalization of accommodations exacerbates the inequalities that disability accommodations are tasked to relieve.

Expanding on this point, my view is that this process of verification also fosters an ethos of distrust toward disabled people. In her work on institutional trust, Nancy Nyquist Potter uses the notion of 'practices of distrust' (Potter 2002: 24) to designate prophylactic measures 'designed to protect organizations . . . from the harms that would accrue from breaches of trust' (Potter 2002: 24). In the case that concerns us, universities require medical certification of a person's disability in order to protect themselves from potential malingering. In addition to privatizing disability knowledge and discrediting experiential knowledge, the accommodations model thus also implicitly relies on the ableist (and often racist, sexist, and classist) trope of disability fraud, according to which a considerable number of people lie about or exaggerate their disability status in order to

\footnotetext{
${ }^{3}$ My framing of access as an action verb is inspired by Leah Lakshmi Piepzna-Samarasinha's description of access as a labor of love and care, first, and by their forceful description of love not as a nonpolitical, static state, but as 'a muscle or an action verb or a survival strategy' (Piepzna-Samarasinha 20I 8: 78).
} 
unlawfully gain social benefits and sympathy (Dorfman 20I9; Samuels 2014). This stigmatizing trope reproduces harmful stereotypes by portraying disabled people as manipulative and ill intentioned. Furthermore, a strict reliance on the medical-industrial complex to certify disability threatens those who are already at risk of violence and discrimination within this complex, including for example trans and gender nonconforming people, working-poor people, people of color, substance users, and inmates.

In actuality, studies investigating the experiences of disabled students in academic institutions reveal a vastly different picture. Many disabled students (and especially students with psychiatric disabilities) report experiencing barriers related to the accommodation process. These barriers include fear of reprisal and of negative future ramifications, fear of negative interactions with individuals in positions of power, and the discomfort associated with the lack of private disclosure opportunities with trustworthy peers (Lyman et al. 20r6; Smith, Woodhead, and Chin-Newman 2019). In addition to these worries, students often do not know what accommodations are available to them (Cole and Cawthon 2015). These compounding factors lead many of them to keep their disability status anonymous (Grimes et al. 20I8). The process of disclosing one's disability to obtain legal accommodations regularly forces disabled people to reveal aspects of their private lives to medical practitioners, professors, employers, colleagues, and administrators. Mia Mingus explains that instances of 'forced intimacy' are a 'common, daily experience [for] disabled people [who are] expected to share personal parts of [themselves] to survive in an ableist world' (2017) and to 'get safe, appropriate, and good access' (2017). The expectation that disabled people will need to share personal information 'to get basic access' (20I7) is an underlying feature of bureaucratic approaches. As Katie Rose Guest Pryal (20I6) writes, 'the accommodations model depends on invasions of privacy to work'. Overall, the bureaucratization of disability knowledge introduces new barriers that disenfranchise many disabled people from safe and reliable access. By framing disability as a medical fact of the body that must be externally corroborated, this approach positions disabled people as inherently untrustworthy and imposes breaches of intimacy as a requirement for obtaining accommodations.

The dominant framework for thinking about access transforms access into a matter of minimal legal compliance. Legalistic approaches fail to recognize how key phenomenological aspects of embodied experience (that is, intersubjectivity, temporality, spatiality) are concretely lived; these approaches devalue lived knowledge in favor of the medicalization and bureaucratization of disability status. But the conflation of access with the provision of legal accommodations presents a further issue. It is very possible, after all, that in spite of the implementation of 'best practices' and accommodations, and although every box has been ticked on the accessibility checklist, disabled people will not feel like they belong in a particular space. Put bluntly, accommodations in themselves do nothing to transform how social belonging is imagined and practiced in the first place. To understand how we create access and transform ableist social worlds, we must address a set of prior philosophical questions concerning belonging. 


\section{A Disoriented Phenomenology of Spatial Belonging}

In previous work, I described belonging phenomenologically as the bodily cued experience of being at grips with the world and of sharing it with others (Lajoie 20I9). The experience of belonging is characteristically varied; it cannot be described monolithically, because belonging is ongoingly negotiated in temporally extended lived situations and interpersonal dynamics. I also do not think that our sense of belonging univocally requires that body and world be seamlessly integrated or optimally bound. The privilege of an indistinguishable fit with the world, in oppressive social worlds, is neither desirable nor universal. But our embodied rootedness in the world-the ways in which we learn, grow, explore, and dwell in worldly spaces—holds valuable insights for the study of access. By examining how, when, and where we belong (or do not belong), we will better understand what it means to create accessible worlds.

Our experience of space offers key insights into the nature of belonging. From a phenomenological point of view, space is not a fixed, singular, and objective entity. Rather, spaces are shaped by the projects and bodily intentions of those who inhabit them (Husserl I997; Jacobson 2004; Merleau-Ponty 20I2). Spaces are variously encountered by differently positioned subjects, both in the narrow sense that spaces appear for us in relation to our own bodily coordinates and capacities, and, more generally, in the sense that they are formed through sedimented histories, both individual and collective, and through which we perceive them. These phenomenological insights are well reflected in the work of scholars of disability, design historians, and feminist and critical race theorists who emphasize that spaces are dynamically modulated, this time by social norms, attitudes, practices, and policies (Dolmage 20I7a, 20I7b; Hamraie 20I6a; 20I6b; 20I7; Lipsitz 2007; Mills 1997; Williamson 2019). To return to a point made earlier, for example, white, middle-class, neurotypical classrooms are far from being neutral. Classrooms are organized around a set of familiar bodily comportments (such as scheduled breaks, fast-paced discussions, racializing and gendered perceptions, aural communication, self-restraint and obedience) that establish the grounds for a highly normalizing motor and affective sensorium. Spaces, Ahmed reminds us, do not offer a ground for all of our lives and instead '[take] the shape of the motility of certain skins' (2006: I60) and are 'shaped by the directions taken by some bodies more than others' (2006: I60). Furthermore, the ways in which some bodies orient themselves in the world and build a shared reality can fundamentally exclude others who are made to feel out of place. More bluntly, relations of power and domination are inscribed in the spatial organization and inhabitance of shared lifeworlds.

The deeper point that follows from this conception of space is that our modes of spatial inhabitance are neither entirely autonomous or self-governed, nor exclusively voluntary. We are not pure acting subjectivities in a world that functions as a receptacle for our intentions. Instead, the phenomenology of space teaches us that our experience of orienting ourselves in the world has a chiasmic structure. We find anchorage in our surroundings through 'a certain possession of the world by [our] body, a certain hold [our] body has on the world' (Merleau-Ponty 20I2: 
299). But the world, too, has a certain hold on our body and the spaces that we inhabit are shaped by histories of inhabitance that are also histories of use. Spaces elicit responses from us in the form of perceptions, movements, sensations, and feelings. In some cases, our bodies achieve an equilibrium with their surroundings: what Merleau-Ponty would call a 'pact' is established that allows us to dwell in a particular place without fearing that the ground under our feet will suddenly give way. This equilibrium, however, inheres strictly neither to our bodies nor to the world. Rather, our feeling of being oriented arises through the experience of a meaningful encounter between body and world. In other cases, the equilibrium between our body and the world is threatened or lost. Spatial environments can just as well offer a ground for the exercise of our freedom and agency as they can throw us off course, restrain and isolate us, or make us feel adrift, alienated, and out of place. My disoriented approach to the phenomenology of belonging begins with these moments when bodies and worlds do not synch up.

In her analysis of whiteness, wealth, and cisnormative masculinity, Nirmal Puwar borrows Pierre Bourdieu's notion of habitus to describe the 'tacit normativity-of which the body is the prime site-that governs the social game' (Puwar 2004: I 26) of institutions. In relation to somatic norms, some bodies are like fish in water' (2004: I27); they naturally feel at home and at ease. On the field of social relations, some players are 'perfectly adapted. . . they take up the position of a "virtuoso", (2004: I 26). Puwar's notion of 'ontological complicity' captures the 'ease, grace, assurance, familiarity, and cadence' (2004: I26) with which these players seamlessly synch their habitus with the demands of their social world. Puwar's analysis focuses on a person's complicity with whiteness, wealth, and cisnormative masculinity. But we must expand this account and consider, too, how somatic norms of able-bodiedness remains undisturbed by the inclusion of disabled bodies in academic spaces. I view ontological complicity with dominant norms as a means of orienting oneself in space; or, to emphasize the reverse pole of this chiasmic relation, it implies spaces becoming 'like a second skin that unfolds in the folds of the body' (Ahmed 2006: 9). Those who are ontologically complicit with dominant somatic norms might feel as though spaces belong to them because others do not belong in them: these 'others' are 'marked out as trespassers [and] space invaders' (Puwar 2004: 8). Now, importantly, space invaders may very well, in theory and in practice, be included, but they are still figured as 'belonging elsewhere' (Puwar 2004: 42).

When examined in a phenomenological register, Puwar's account indicates that the exclusionary organization of space demarcates possibilities for belonging. Those whose bodies are constantly registered as dissonant in relation to the somatic norms that 'govern' social lifeworlds are excluded from the cultivation of a meaningful sense of belongingness. In sum, spatial exclusion is ontologically operative. Phenomenologically, some 'others' are not encountered as cointentionalities within a shared horizon of coexistence, but rather as disrupting the grounds of intersubjective reciprocity. Disabled people, for example, are encountered as '[noticeably] departing from the desired and expected' (Titchkosky 20II: 5) bodyminds that count as 'normal'. They are made 'into a presence that is not imagined, not welcomed' (Titchkosky 20I I: 26), even while they are here. 
To be clear, the account of belonging that I propose does not imply that we are either 'fish in water' or 'fish out of water'. I do not believe that we are always either entirely complicit with or entirely alienated from dominant somatic norms. In many cases, we may be ambiguously positioned in relationship to them. A white tenured faculty professor with a nonvisible disability, for example, may fit in seamlessly at departmental meetings alongside her white faculty members. When she contributes to departmental meetings, her propositions are warmly encouraged by her colleagues. Later during the same meeting, however, she may feel out of place when her colleagues complain about the needs of their disabled students. Alternatively, a graduate student may feel safe and at ease confiding in a feminist colleague over lunch but begin feeling uneasy as soon as she steps into her mostly white classroom later that day. The sight of an abuser in the hallway, the feeling of being racially tokenized at a conference, or the experience of receiving a disrespectful email from a professor can immediately shift our bodily inhabitance of a purportedly 'inclusive' space. It is rarely the case that we either fully belong or do not belong. And, for many of us, it is unlikely that we will ever develop a monolithic sense of belonging within the institutions that we inhabit. But the shifting ground of our sense of belonging reminds us that the ontological complicity of certain bodies-those who frequently move with 'ease, grace, assurance, familiarity, and cadence' (Puwar 2004: I26) through the reproduction of somatic normalcy-with some spaces fundamentally depends on the exclusion of others from these spaces.

Ableist lifeworlds generate serious disorientations for disabled people that seriously impede the experience of belonging. In her work on disorientation, Ami Harbin explains that disorientation may vary in kind, but they are generally multidimensional, existentially layered experiences that mark the '[feeling] of being out of place, unfamiliar, or not at home' (2012: 262)' in the world. Ahmed emphasizes a similar connection to belonging when she writes that '[disorientations] can be a bodily feeling of losing one's place, and an effect of a loss of a place' (Ahmed 2006: I60). On my view, disorientations speak to the possibility of losing one's hold on the world. In moments of disorientation, familiar habits, gestures, or patterns of thought are called into question. Disorientations are not an oddity. Rather, all of us will encounter these types of experiences at least once in our lives, albeit with very different levels of exposure and available support to navigate them. Our lives are inevitably affected by unexpected challenges, new encounters, latent tensions, moments of doubt, and a wealth of other experiences revealing that we are, from the start, open to a world of sense that we do not control. In fact, although they have received very little philosophical attention thus far, disorientations are an important part of human experience. And, while some disorientations are harmful and oppressive- and they can be the result of structural oppression, as we will see-disorientations are not necessarily debilitating. In some cases, they can be a reminder of the possibility of things becoming otherwise, as we clear past dwellings and develop orientations that value our growth, healing, or curiosity as embodied beings. Unlearning internalized racism or ableism, leaving an abusive relationship, coming out as queer, acquiring a disability, or rekindling a relationship with a long-lost 
parent are all examples of experiences that might both prompt important disorientations and nurture important processes of self-transformation and discovery. In most cases, the experience of momentarily losing one's grip does not compromise the possibility of cultivating a deeper sense of belonging in the world.

However, the lived experience of disability in ableist social worlds produces disorientations that $d o$ compromise this ground because (I) they are lasting (that is, they are characteristic of the everydayness of disabled lives and enduring rather than fleeting or temporary); (2) they are structurally enforced (that is, they are conditioned by historical-material conditions of oppression and the social and political exclusion of disabled people); and (3) they are harmful (that is, they are both affectively and physically draining and existentially damaging). In addition to generating stigma and harm, the sustained experience of 'misfitting' (Garland-Thomson 20II) marks disabled bodies as burdensome and as constantly out of place, thus threatening the very existential security that makes dwelling possible. Here, I would add that this experience is existentially disorienting even if disabled people do develop strategies to survive in ableist worlds and routinely expect the feeling of misfitting. Many disabled people come to expect that they will be excluded from certain spaces due to lack of access, such that they learn to anticipate these exclusions. But the 'ordinariness' of disablist exclusion does not make it any less disorienting, first, because one can be disoriented by something that she anticipated (such as the death of a loved one in palliative care) and, second, because however predictable they may be at a reflexive level, the disorientations that I am describing are initially felt at a pre-reflexive, bodily level. I view the disorientations sustained through repeated lack of access as an example of what Annika Konrad names 'access fatigue', a term she coined to describe the 'wearing out' that results from constantly having to seek accommodations and anticipate barriers at every stage in one's everyday life (Konrad 202 I: I80). S. Kay Toombs, a phenomenologist living with multiple sclerosis, describes the tiredness resulting from the routine experience of struggling with worldly engagement in ableist environments as 'existential fatigue' (Toombs I995: I5). The simplest of tasks become burdensome, thus tempting her to 'curtail her involvement in the world' (Toombs I995: I 5), to retreat from public existence. Both Toombs's and Konrad's accounts of fatigue indicate that the enduring sense of being out of place and of being treated as a burden or an afterthought is damaging. At the deepest level, it is inimical to the development of a rich sense of belonging in the world and to the possibility of flourishing therein.

I worry that three normative conclusions could be drawn from my claims, so I warn against them. First, I am not prescribing or recommending any particular experience of belonging or staking a claim about 'true' belonging. This would be contradictory to the disoriented account of belonging that I seek to provide. The experience of belonging is neither rigidly established once and for all nor constricted to a specific place, comportment, or attitude. Orienting oneself and finding one's way in the world is not strictly about the here and now of our physical dwellings, or even strictly about our relations to others who are here, now. The experience of belonging is spatially and temporally expansive; it encompasses a wide range of relationships (such as to place, others, ancestry, 
matter, land, spirituality, activism, language). Learning to dwell in the world is not a linear or well-defined process. Rather, it is 'an ongoing existential 'activity" (Jacobson 2010: 224). What is at stake in belonging is not so much a definite, univocal pact as a genuine becoming marked by our changing situation and relationships in the world. Both are swayed by unpredictable courses (hence my earlier emphasis on access as a temporally extended, open-ended process). The sway and unpredictability of these courses is anchored by trusting relations with ourselves, with the world, and with others. Indeed, the robustness of these relations is precisely what allows us to explore the complexity of our changing bodyminds. Both poles-lability and familiarity, or adaptability and robustnessare important. However, when our lives are systematically disrupted and called into question by exclusions that devalue our existence, disorientations occur that fundamentally erode our trust in ourselves and in others.

Secondly, I do not believe that our lives must be exclusively oriented. This is neither possible nor desirable. I have argued elsewhere that a blanket notion of belonging as seamless body-world complicity simply does not function as an apposite metaphor for a life in which serious disorientations are possible (Lajoie 2019). Descriptions of 'inconspicuous, unobtrusive, and nonobstinate' (Diedrich 200I: 2I2) embodiment fall short; they do not offer an accurate account of the complex ways in which bodies inhabit the world. The crip sense of belonging that I have in mind neither precludes the possibility of disorientations, nor devalues them. Our role, as Harbin reminds us, is not to 'interact with [disoriented individuals] in ways that reorient [them]' (Harbin 20I6: I68). Rather, my claim is that our responsibility in creating accessible worlds is to dismantle the systems that cause lasting, structurally enforced, and harmful disorientations for non-normative bodyminds. The role of individuals and communities is to nurture each person's capacity to develop trusting and fulfilling relations in and with the world around her, as this process includes the possibility of disorientations.

Finally, I am also not claiming that we should strive to develop a sense of belonging in racist, classist, heterosexist, and ableist lifeworlds. I believe, instead, that those of us who do benefit from our ontological complicity with dominant somatic norms must actively ask ourselves where we feel as if we belong (or not) and why. We must reflect on how our inhabitance of spaces is entangled with the histories of exclusion that have helped shape them. This, too, is an essential part of rethinking access.

\section{Conclusion}

My aim in this essay has been to revert access back into a question and to defamiliarize our understanding of this notion. Our dominant bureaucratic frameworks for thinking about access in higher education remain committed to a conception of disability as an individual problem to be 'fixed'. Mingus sums up this failure: 'Able bodied people treat access as a logistical interaction, rather than as a human interaction' (Mingus 20I7). Legalistic approaches have dangerously depoliticizing effects. Within this framework, the liberation of disabled people is merely 'boiled down to logistics' (Mingus 20II; see also Valentine 2020). While 
accommodations can be a part of what it means to create accessible worlds, they do not 'solve' anything in themselves. By deferring to the minimal provision of legally mandated accommodations, academic institutions fail to recognize ableism as a multilayered, intersectional, and structural issue that requires deeper social transformations. Instead, institutions transform disabled people into 'question marks' in the margins of institutional life-questions too often left unasked and unanswered.

Ableist practices of exclusion generate serious disorientations for disabled people. Importantly, the harms of ableist exclusion are linked to and intersect with other forms of discrimination against others who are marked as 'trespassers' and have historically been denied access to social space. The segregation of disabled and otherwise nonnormative bodies from public space has a long history. Susan M. Schweik's (2009) detailed history of the 'Ugly Laws', which prohibited diseased, maimed, or deformed persons from appearing in public well into the I970s, shows that the segregation of 'deviant' bodies is well connected to practices of racial segregation. Asylums, 'madhouses', 'special schools', psychiatric institutions, and prisons have also served (and continue to do so, in their contemporary iterations) to segregate Mad and disabled people from the public sphere, particularly along specific axes of race, class, and gender. In fact, the segregation of bodies and the parceling of stolen land is at the heart of the project of public education in the United States. In I 862, the adoption of the Morrill Act consolidated the theft of Indigenous land for settler-colonial educational purposes. The democratization of access to education in the United States relies on practices of expropriation and legacies of violence.

Thus, while it is important that we continue to talk about disability when we talk about access (and while we should be wary of discussions of access that exclude all mention of disability), a critical approach to access views disability as fundamentally intertwined with other forms of oppression based on race, sex, gender, sexual orientation, class, size, and nationality (Mingus 20I I, 20I7; Piepzna-Samarasinha 20I8; Schalk and Kim 2020). And, while we must continue to fight for access, we also need to ask ourselves what it would mean to be offered a seat at the table and whose tables we are fighting to access. In the words of Mingus, again, 'We don't simply want to join the ranks of the privileged; we want to dismantle those ranks and the systems that maintain them' (Mingus 20II). These ranks include those reproduced by ableism and saneism as these systems interlock with white supremacy, cis-heteropatriarchy, colonialism, capitalism, and environmental racism. Ultimately, what matters most is not the 'inclusion' of disabled people in ableist spaces. What matters is that we imagine modes of sharing space that radically transform practices of relationality and belonging. Only on this basis can we work toward creating access. 


\section{References}

Abrams, Thomas. (2015) 'Disability and Bureaucratic Forms of Life'. Nordic Journal of Science and Technology Studies, 3, I2-2I.

Ahmed, Sara. (2006) Queer Phenomenology: Orientations, Objects, Others. Durham: Duke University Press.

Ahmed, Sara. (2012) On Being Included: Racism and Diversity in Institutional Life. Durham: Duke University Press.

Ahmed, Sara. (20I4) 'Dated Feminists'. feministkilljoys (blog), April 8, 20I4. https://feministkilljoys. $\mathrm{com} / 20 \mathrm{I}_{4} / 04 / 08 /$ dated-feminists/.

Ahmed, Sara. (2019) What's the Use? On the Uses of Use. Durham: Duke University Press.

Cole, Emma V., and Stephanie Cawthon, Stephanie W. (2015) 'Self-Disclosure Decisions of University Students with Learning Disabilities'. Journal of Postsecondary Education and Disability, 28, I63-79.

Diedrich, Lisa. (200I) 'Breaking Down: A Phenomenology of Disability'. Literature and Medicine, 20, 209-30.

Dolmage, Jay. (2017a) Academic Ableism: Disability and Higher Education. Ann Arbor: University of Michigan Press.

Dolmage, Jay. (20I7b) 'From Steep Steps to Retrofit to Universal Design, from Collapse to Austerity'. In Jos Boys (ed.), Disability, Space, Architecture: A Reader (New York: Routledge), I03-I3.

Dorfman, Doron. (2019) 'Fear of the Disability Con: Perceptions of Fraud and Special Rights Discourse'. Law and Society Review, 53, I05 I-9I.

Duchan, Judith Felson. (2006) 'Providing a Place in the New History of Disabilities for Communication Access’. Disability Studies Quarterly, 26 (n.p.). http://dx.doi.org/Io.I806I/ dsq.v26i2.675.

Fritsch, K. (2013) 'The Neoliberal Circulation of Affects: Happiness, Accessibility and the Capacitation of Disability as Wheelchair'. Health, Culture, and Society, 5, I35-49.

Garland-Thomson, Rosemarie. (20I I) 'Misfit: A Feminist Materialist Disability Concept'. Hypatia: A Journal of Feminist Philosophy, 26, 59I-609.

Grimes, Susan, Erica Southgate, Jill Scevak, and Rachel Buchanan. (20I8) 'University Student Perspectives on Institutional Non-disclosure of Disability and Learning Challenges: Reasons for Staying Invisible'. International Journal of Inclusive Education, 23, 639-55.

Hamraie, Aimi. (2016a) 'Beyond Accommodation: Disability, Feminist Philosophy, and the Design of Everyday Academic Life'. philoSOPHIA, 6, 260-72.

Hamraie, Aimi. (2016b) 'Universal Design and the Problem of "Post-Disability" Ideology'. Design and Culture, 8, 285-309.

Hamraie, Aimi. (2017) Building Access: Universal Design and the Politics of Disability. Minneapolis: University of Minnesota Press.

Harbin, Ami. (20I2) 'Bodily Disorientation and Moral Change'. Hypatia: A Journal of Feminist Philosophy, 27, 26I-80.

Harbin, Ami. (2016) Disorientation and Moral Life. New York: Oxford University Press.

Husserl, Edmund. (1997) Thing and Space: Lectures of 1907. Translated by Richard Rojcewicz. Dordrecht: Springer.

Jacobson, Kirsten. (2004) 'Agoraphobia and Hypochondria as Disorders of Dwelling'. International Studies in Philosophy, 36, $3 \mathrm{I}-44$.

Jacobson, Kirsten. (20I0) 'The Experience of Home and the Space of Citizenship'. Southern Journal of Philosophy, 48, 219-45.

Konrad, Annika. M. (202I) 'Access Fatigue: The Rhetorical Work of Disability in Everyday Life'. College English, 83, I79-199.

Lajoie, Corinne. (2019) 'Being at Home: A Feminist Phenomenology of Disorientation in Illness'. Hypatia: A Journal of Feminist Philosophy, 34, 546-69.

Lipsitz, George. (2007) 'The Racialization of Space and the Spatialization of Race: Theorizing the Hidden Architecture of Landscape'. Landscape Journal, 26, 10-23.

Lyman, Michael, Mark E. Beecher, Derek Griner, Michael Brooks, John Call, and Aaron Jackson. (20I6) 'What Keeps Students with Disabilities from using Accommodations in Postsecondary 
Education? A Qualitative Review'. Journal of Postsecondary Education and Disability, 29, I $23-40$.

Maclaren, Kym. (20I4) 'Touching Matters: Embodiments of Intimacy'. Emotion, Space and Society, I3, 95-IO2.

Maclaren, Kym. (20I8) 'Intimacy as Transgression and the Problem of Freedom'. Puncta: Journal of Critical Phenomenology, I, I8-40.

Merleau-Ponty, Maurice. (20I2) Phenomenology of Perception. Translated by Donald A. Landes. New York: Routledge.

Mills, Charles W. (I997) The Racial Contract. Ithaca, NY: Cornell University Press.

Mingus, Mia. (20I I) 'Changing the Framework: Disability Justice. How our Communities can Move beyond Access to Wholeness'. Leaving Evidence (blog), February I2, 20II. https:// leavingevidence.wordpress.com/201 I/O2/I $2 /$.

Mingus, Mia. (20I7) 'Forced Intimacy: An Ableist Norm'. Leaving Evidence (blog), August 6, 2017. https:/leavingevidence.wordpress.com/20I7/08/06/forced-intimacy-an-ableist-norm/.

Piepzna-Samarasinha, Leah Lakshmi. (2018) Care Work: Dreaming Disability Justice. Vancouver: Arsenal Pulp Press.

Powell, Annette Harris. (2007) 'Access(ing) Habits, Attitudes, and Engagement: Re-thinking Access as Practice'. Computers and Composition: An International Journal for Teachers of Writing, 24, I6-35.

Price, Margaret. (20I I) Mad at School: Rhetorics of Mental Disability and Academic Life. Ann Arbor: University of Michigan Press.

Price, Margaret. (2015) 'The Bodymind Problem and the Possibilities of Pain'. Hypatia: A Journal of Feminist Philosophy, 30, 268-84.

Price, Margaret. (20I6) 'Un/Shared Space: The Dilemma of Inclusive Architecture'. In Jos Boys (ed.), Disability, Space, Architecture (London: Routledge), I49-67.

Potter, Nancy Nyquist. (2002) How Can I Be Trusted? A Virtue Theory of Trustworthiness. Lanham, MD: Rowman \& Littlefield.

Pryal, Katie Rose Guest. (20I6) 'Accessibility v. Accommodation (part I)'. Blog post, Katie Rose Guest Pryal (website), April 4, 20I6. https://katieroseguestpryal.com/20I6/04/04/accessibility$\mathrm{v}$-accommodation-part- $\mathrm{I} /$.

Puwar, Nirmal. (2004) Space Invaders: Race, Gender and Bodies Out of Place. Oxford: Berg.

Samuels, Ellen. (20I4) Fantasies of Identification: Disability, Gender, Race. New York: New York University Press.

Schalk, Sami. (2018) Bodyminds Reimagined: (Dis)ability, Race, and Gender in Black Women's Speculative Fiction. Durham: Duke University Press.

Schalk, Sami, and Jina B. Kim. (2020) 'Integrating Race, Transforming Feminist Disability Studies'. Signs: Journal of Women in Culture and Society, 46, $3 \mathrm{I}-55$.

Smith, Sara A., Erin Woodhead, and Christina Chin-Newman. (2019) 'Disclosing Accommodation Needs: Exploring Experiences of Higher Education Students with Disabilities'. International Journal of Inclusive Education. Published ahead of print. https://doi.org/I0.1080/13603 I I6. 2019.1610087.

Stramondo, Joseph. (2015) 'The Medicalization of Reasonable Accommodation'. https:// philosophycommons.typepad.com/disability_and_disadvanta/20I5/0I/the-medicalization-ofreasonable-accommodation-in-higher-education.html (Accessed April 30, 2020) (site discontinued).

Schweik, Susan. (2009) The Ugly Laws: Disability in Public. New York: New York University Press.

Toombs, S. Kay. (1995) 'The Lived Experience of Disability'. Human Studies, I8, 9-23.

Titchkosky, Tanya. (2007) Reading and Writing Disability Differently: The Textured Life of Embodiment. Toronto: University of Toronto Press.

Titchkosky, Tanya. (20I I) The Question of Access: Disability, Space, Meaning. Toronto: University of Toronto Press.

Titchkosky, Tanya and Rod Michalko. (2012) 'The Body as a Problem of Individuality: A Phenomenological Disability Studies Approach'. In Dan Goodley, Bill Hughes, and Lennard Davis (eds.), Disability and Social Theory: New Developments and Directions (London: Palgrave Macmillan), I27-42. 
Valentine, Desiree. (2020) 'Shifting the Weight of Inaccessibility: Access Intimacy as a Critical Phenomenological Ethos'. Puncta: Journal of Critical Phenomenology, 3, 76-94.

Williamson, Bess. (2019) Accessible America: A History of Disability and Design. New York: New York University Press.

Wilson, Jan Doolittle. (2017) 'Reimagining Disability and Inclusive Education through Universal Design for Learning'. Disability Studies Quarterly, 37 (n.p.). http://dx.doi.org/I0.I806I/dsq. v37i2.54I7. 